Cite as: Roth, W.-M. (2012). Rules of bending, bending the rules: The geometry of conduit bending in college and workplace. Educational Studies in Mathematics. DOI: 10.1007/ s10649-011-9376-4

\title{
Rules of Bending, Bending the Rules: The Geometry of Electrical Conduit Bending in College and Workplace
}

Wolff-Michael Roth

Using cultural-historical activity theory as my framework, I report an empirical study of how electrician apprentices learn to bend electrical conduits in college and on the job. The requirements for doing well in the two locations are very different: exhibiting knowledge of trigonometry, on the one hand, and doing a good job that makes bending and subsequent pulling of wires practical. Formal trigonometry is the reference in the classroom, whereas rules of practice are the main references on the job. In each case, the practices orient themselves to the Canadian codebook, which provides a description that the inspector uses as his/her reference when checking for approval. However, the sharp differences between the two forms of practice and the contradictions arising from them are reintegrated into the stories that are constitutive of the community of practice. Implications are discussed with respect to the concept of "boundary crossing" through the lens of cultural-historical activity theory and its concepts for the development of the individual: subjectification, which describes the changes within an activity system (school, work) and personality, the changes the individual undergoes as s/he moves repeatedly between systems of activity.

Keywords College mathematics $\bullet$ workplace mathematics $\bullet$ boundaries $\bullet$ culturalhistorical activity theory $\bullet$ subjectification $\bullet$ personality

\section{Introduction - on activities and boundaries that separate them}

The purpose of this study is to present empirical data on the mathematics electrician apprentices learn in their formal schooling and the very different mathematical practices they encounter in the everyday work on the job. I use the results to reflect on the relation 


\subsection{On boundaries and boundary crossing}

Since around the publication of Cognition in Practice (Lave, 1988), much has been written about the differences between formal mathematics as taught in schools and colleges and mathematics in a variety of work-related activities, including packaging goods in dairy factories (Scribner, 1986), banking (Noss \& Hoyles, 1996), selling candy in street markets (Saxe, 1991), and hatching salmon (Roth, 2005). Studies show time and again that 
regardless of level of instruction, practitioners - such as bookies with 0 to 11 years of schooling (Schliemann \& Acioly, 1989) - tend to be highly proficient in their day-to-day practice. However, the ability to solve and the number of correct answers on school-like problems often exhibit statistically significant relations with school instruction, even though the latter does not generally influence the specific nature of chosen solution approaches. There appear to be real boundaries between the kinds of practices between school, on the one hand, and the everyday praxis of work and life, on the other hand. Practitioners especially feel that those arriving on the job from formal schooling know very little and have to begin by learning first what really matters on and to the job (Lee \& Roth, 2004). At the same time, those with too much formal knowledge are often characterized in the field as "too smart," destined for some office job or a job where formal knowledge is appreciated (Lee \& Roth, 2006). It does not surprise, therefore, that there is a lot of boundary and boundary crossing talk in recent scholarship on the transitions between school and work (e.g., Tuomi-Gröhn \& Engeström, 2003).

There are strong theoretical reasons from the philosophy of difference why the concept of boundary crossing does not make sense, for each culture is not a self-identical entity but already constitutes a mêlée of socio-cultural practices and spaces that are continually hybridized into new forms of practices and spaces (Nancy, 1993). Rather than different spaces and boundaries between them, we actually observe (a) a continuous hybridization of cultural practices and identities and (b) an integration of contradictions within and between practices and identities. Are there other ways of theorizing the different mathematical practices that distinguish formal educational contexts - secondary schools, vocational schools, universities - and the everyday work praxis? Indeed there are, one being cultural-historical activity theory in its original formulation and the way it integrates a person's trajectories across multiple activities.

\subsection{Knot-worked object/motives constitute personality}


Cultural-historical activity theory allows us to think about what happens to an individual who participates within an activity over time and whose trajectories takes it through/across different activities in the course of a day, week, month or year (Leontjew, 1982). The category activity refers to the structure of a cultural-historical productive process that contributes to the maintenance and transformation of society as a whole by accomplishing one part of the total labor required (Roth \& Lee, 2007). Activities are subject to cultural-historical change processes, in fact, they produce cultural and historical changes; and, with these, the subject of productive activity also comes to be changed on both a material plane (e.g., more skilled, economical, physically strengthened or burned out) and an ideal plane (e.g., consciousness, understanding, and discourse) (Marx \& Engels, 1962; Vygotsky, 1989).

The analytic category of subjectification (Roth \& Radford, 2011) brings together the idea of the cultural-historical subject as agent in the activity system and the idea of the subjectification process from philosophy of politics (Rancière, 1999). I understand subjectification to be a process by means of which the individual person continuously changes: as the productive subject of labor, the person becomes more knowledgeable and skilled and as the patient of activity, the person is subject(ed) to the activity and the societal relations that come with it. A person undergoes subjectification in each and every activity where s/he participates in the course of the day, week, or month.

Human individuals do not just take part in single activities but in fact participate in many activities on the same day, often in multiple activities simultaneously. However, the conscious object/motives that orient the different activities have different degrees of importance to the individual: from his/her perspective, there is a hierarchically organized knotwork of object/motives that intertwines the different activities (Leontjew, 1982). The knots are not the result of "the biological or mental forces of the subject, which lie within it, but are created in the system of relations that the subject enters" (p. 178). Thus, the hierarchical connections between object/motives "constitute the 'knots' for personality" (p. 


\section{Research context}

Over more than a decade, my research team has conducted ethnographic studies of knowing and learning mathematics (and science) in a variety of settings: undergraduate and graduate science students during laboratory and field internships, fish culturists, electricians, mariners, dentists, environmentalists, and teachers. In each of these contexts, 
we have drawn on a particular combination of methods (Roth, in press) that brings together more traditional participant observation with apprenticeship as field method (Coy, 1989), where the researcher signs up as a helper or, in the case of the electricians, completes, a trade apprenticeship program. In all cases, we also use an "interactive ethnographic design" where the researcher in the field continually debriefs with another researcher. In addition, we meet regularly for interaction analysis sessions, whereby the entire research team and other interested individuals engage in collective analysis and discussions of interpretations.

In this particular study, one of my graduate students (R. Racca) enrolled in a four-year training program at a local college to become a licensed electrician (Trade Interprovincial Qualification) and worked as apprentice for four local companies. Throughout the program, he kept field notes, shot photographs, and photocopied pertinent documents; he also conducted interviews. To provide further depth to the data, I also have monitored various online forums, in which electricians from around the world discuss a variety of problems arising from their work, including conduit bending. I studied code and practice and have personal experience of designing a complete wiring system, followed by observing the electrician hired to complete the job.

The college curriculum focuses on formal knowledge. Within the first month of the program, students must master units on solving mathematical problems (problems involving whole numbers, fractions, decimal fractions, ratios and proportions, percentages, powers and roots, graphs, and geometry) and sections on science (properties of matter, thermodynamics, mechanical physics). The curriculum also includes several shop units, where students erect scaffolds and ladders, use specialized power tools, and cut, thread, and bend (rigid) electric metallic conduit.

\section{The mathematics of conduit bending}

There are two very different fields of knowing that an apprentice encounters during training, school, and work, held together by a third, the electrical code of Canada. In the 
following subsections, I describe each of these fields and then articulate how electrical apprentices knotwork them.

\subsection{Conduit bending - the electrical code}

For safety reasons, electrical wiring has to be shielded and grounded, which is achieved by running it, where necessary, through electrical metal tubing (EMT) or electrical conduits (Figure 1). The electrical code of Canada does not contain reference to mathematics but specifies general rules for bending electrical metal tubing such as the minimum radius of the turn - e.g., Rule 12-922(1) states "Where conductors are drawn into a raceway, the radius of the curve to the centre line of any bend shall be not less than as shown in Table 7" (CSA, 2003, p. 3). A table then specifies the minimum radius to the centre of the conduit for a trade size $1 / 2$ inch of conduit $(16 \mathrm{~mm})$ to be 4 inches $(102 \mathrm{~mm})$. The rule also specifies that the bends have be made without undue distortion of the electrical metal tubing and without injury to its inner or outer surfaces. The bends must be round and should be made with the proper tool and may not be made by bending around some object such as a car bumper or a tree (Knight, 2002). Rule 12-942 states that there cannot be more than a total of four $90^{\circ}$ bends. This code is the reference both in and to college and workplace practices.

««««《« Insert Figure 1 about here »"»»»»»

\subsection{Conduit bending - in college (theory and hands-on)}

In college, the students intending to become electricians are taught conduit bending theory. The students in our study were provided with conduit, benders, and a standard textbook on the topic, Electricians Guide to Conduit Bending (Cox, 1982). Students are required to study basic trigonometry: sine, cosine, tangent, cotangent, secant, and cosecant. The textbook provides students with "magic circles" to remember how to calculate such functions as the sine, cosine, and tangent (Figure 2). By placing a finger or thumb on one of the letters, the device tells students the mathematical operation to conduct. Thus, for 
example, to calculate the sine, the student places a finger on the "S," leaving the other two letters open, with the " $\mathrm{O}$ " above the line and the " $\mathrm{H}$ " below the line, which translates into the mathematical operation $\sin (\Omega)=0 / \mathrm{H}$, where $\Omega$ is the desired angle (Figure 2). Equivalently, if the student wants to know the length of the hypotenuse given the sine and the opposite side, then $\mathrm{s} / \mathrm{he}$ places the finger on the "H." As a result, $\mathrm{s} /$ he calculates $\mathrm{H}=$ $0 / \sin (\Omega)$. Common angles used are $10^{\circ}, 22.5^{\circ}, 30^{\circ}, 45^{\circ}, 60^{\circ}$, and $90^{\circ}$.

««««« Insert Figure 2 about here $» » ») » »$

Students may be asked to produce an offset for the electrical metal tubing that takes the electrical wires around a 10 -inch beam given an angle of $22.5^{\circ}$. The student uses the magic circle to calculate the required missing hypotenuse (Figure 3). Looking up the sine of $22.5^{\circ}$, the student can get the hypotenuse, which is, the length between the two bends to be

$$
H=\frac{O}{S}=\frac{10}{\sin \left(22.5^{\circ}\right)}=\frac{10}{.3827}=26.1 .
$$

That is, the student marks off on the conduit to be bent a distance of $26.1 \mathrm{inch}$. Because the conduit must be in one piece according to the code, the student also has to calculate where in the conduit the first bend has to lie, that is, how far away from the obstacle. Here, too, the textbook asks students to draw on one of the magic circles.

$$
\text { ««««« Insert Figure } 3 \text { about here »»»»»»» }
$$

In their college course, therefore, the electrical apprentices carry out extensive calculations and measurements to determine angles, their positions on the tubing, and the distances between the angles. Once a student has calculated the distances, s/he uses measuring tape and bender to produce the tubing such that it properly bypasses the obstacle provided. Our fieldwork shows that in the case of an error, the tubing is discarded without any attempt in rectifying the bend. A reanalysis would be asked of the student to ascertain whether there was an error in calculation or measurement. The actual time spent on the task is immaterial in the course, because the only requirement in this self-paced unit is placed on getting the pipe correctly bent. During the research, many students in the 
program struggled with the mathematics, which they, especially after working for a first time as apprentice, tend to find entirely irrelevant to the work they do; and they tend to feel "psyched out" by the examinations they have to take.

In their conduit bending class, those apprentices who begin with the college courses also encounter for the first time a conduit bender (Figure 4). It is not just an unmarked tool, such as a hammer, but a tool that includes different marks and representations, including, on one side, angle measures and markers. On the reverse side, there are numbers corresponding to each angle, which in fact are the cotangent values that correspond to the angles. However, in the college classes, the students do not use these numbers but calculate distances between the bends based on trigonometric calculations. «««««" Insert Figure 4 about here »»»»»»»

A typical offset represented in Figure 3 involves two bends. The student marks off the calculated distance between the two bends. The bender is placed on the tubing such that the arrow (lower photo, Figure 4) points to the first mark on the tubing. Pushing on the handle, the tubing is bent until it is parallel to the line on the tool corresponding to the desired angle. The second bend is accomplished at the second mark in such a way that the entire tubing remains in a plane, that is, rests flat on the floor.

Although the process of increasingly becoming a competent college student, that is, one who passes the exams, subjectification also means going through particular experiences with the formal knowledge that appears to have an existence in its own right, separate from practical knowledge on the job. This is apparent in the following field note:

After getting 97\% on the first year's "Code" exam, I rejoin the ELT program, and I suddenly find myself unable to write the ELT-E "Code" exam - unsure of how to approach preparing for it. I spent two days going over the different sections of the "Code" book that I have covered with the first years: I know that I know the material, but something about how I know the material does not fit the framework of how the 
ELT students work on "Code." I keep "psyching myself out" as far as taking the ELT "Code" exam. (Racca, January 1999)

Psyching oneself out over being successful on an upcoming exam and learning to cope with the associated stress is as much part of becoming a college student as coming to know the geometry of formal conduit bending. Even Racca, who, with a Bachelors degree in science completed the college courses with greater ease and higher grades than others, psyching himself out was integral to his college experience.

\subsection{Conduit bending - in the field}

In contrast to the classroom, conduit bending in the field does not use trigonometry but implements a set of unwritten global rules:

- two 90s: do not exceed a total of $180^{\circ}$ between any two pull points, as greater totals would make pulling harder;

- no dog legs: the tubing must be bent such that it offsets while remaining in the same plane;

- shallow-is-mellow: smaller angles are preferable to larger ones, as it makes pulling easier;

- looks count: the tubing is to be laid such that it runs horizontally and vertically, as long as possible, with a minimum number of couples [places where pipes join] and identical offsets [horizontal displacement required for a pipe to get around an obstacle] in parallel conduits; and

- forgive or forget: errors in bent tubing are corrected, rather than tubing abandoned (cost!), because the tubing is "forgiving."

These are rules of thumb that are adapted such that the electrical code is met, which is the ultimate requirement as the installation is subject to inspection. For example, the practical rule "two 90s" is more stringent than the code but makes the life of the electrician easier. Some electricians feel that code "is 99\% how it works, and 1\% how it looks" and that they 
"can bend a pipe to code but if [they] were try to bend a pipe pretty, it ain't a gonna happen!" Adaptations are necessary, for on the job there are contingencies for laying conduit that have not been apparent to architects and engineers designing the blueprints in the electricians' hands.

In our research, not a single electrician made reference to the textbook approach when bending electrical conduit tubing. The most common is the "multiplier method," which is also described on the operating description that the toolmaker supplies (e.g., Greenlee Textron, 1998). Electricians tend to know the multipliers for the most common angles used in the trade and these are also marked off on the bender (Figure 4, top). Thus, to the set of angles $\left\{10^{\circ}, 22.5^{\circ}, 30^{\circ}, 45^{\circ}, 60^{\circ}\right\}$ the corresponding set of multipliers is $\{5.76,2.60,2.00$, $1.41,1.15\}$. An electrician who wants to produce a 10 -inch offset knows that the distance between the two angles will have to be $d=10$ " * $2.60=26$ ". Although some electricians in our study knew of the multipliers needed to produce the location of the first bend, the location was produced almost exclusively “by feel.” Experienced electricians placed the second bend correctly; and in the exceptional case where the bend was not in a sufficiently accurate position, minor adjustments to the overall length of the electrical metallic tubing were made. My observations of plumbers at work show that such a qualitative approach also is a characteristic of their geometrical practices at work. They tend not to use measuring tape to mark off how much pipe to cut, but use some old piece of pipe that they hold in the place to mark with their finger nail the required length and then, holding it to the material, cut the required piece. If the length does not yield the required length to produce a $90^{\circ}$ angle with another pipe, then they cut off a piece until the required "looks," a more-or-less perfect $90^{\circ}$ angle, is achieved.

Unbeknownst to most electricians, the multiplier method is based on cotangent and cosecant. Thus, given an angle $\Omega$ and $\operatorname{cotan}(\Omega)=$ adjacent/opposite, the adjacent $=\operatorname{cotan}(\Omega)$ * opposite. Here, the multiplier is the cotangent of the desired angle. Similarly, given that $\operatorname{cosec}(\Omega)=$ hypotenuse $/$ opposite, the hypotenuse $=\operatorname{cosec}(\Omega)^{*}$ opposite. The multiplier 
method is easy, as the electricians either remember them - more senior practitioners have them more easily available than more junior members of the field - and some carry "cheat sheets," which contain the multipliers for different angles when these are not available on the tool itself. Our fieldwork shows that the use of easily remembered multipliers is particularly important for young workers: The electricians do not calculate but use the means at hand (markings on the tool) to arrive at an accurate and failure-proof bend.

Apprentices learn the practice of conduit bending from journeymen and senior apprentices. However, instruction seldom is direct. Rather, the apprentice follows orders such as "do a 6-inch offset using 30 degree bends." This forces the apprentice to do much of the bending work, thereby coming to know the multipliers by heart. The journeymen and senior apprentices generally do not explicate their choices but rather follow the rules of thumb that they have learned in the course of their apprenticeship. Bending practices thereby come to be reproduced; and few know the underlying reasons for particular choices and practices. There is also a lot of story telling and story retelling, and these stories embody cultural knowledge that is reproduced and transformed as they are "passed around."

Apprentices also begin to experiment on their own, while still working under the supervision of a journeyman electrician. Ease of calculation and working under the constraints of the actual worksite determines preferences the apprentice develops. The selection of the angles then emerges from a number of contingencies, as exhibited in the following field note in which the journeyman suggests what to do to install $1 / 2$-inch electrical conduit tubing that runs along steel trusses, including an offset bent. Asked by the apprentice about how to do it, the journeyman suggested:

Ideally you want to use twenty-two-degree [sic] bends, 'cause they're the easiest to pull wire through. But the multiplier for those bends is hard to remember and hard to multiply by. Also, when you put in twenty-two-degree bends, you have to look at the markings on the bender to see when you're there. When you work on scaffolding, 
three floors up, you don't want to be bending down to check your markings. Instead you want to put in thirty-degree bends: the multiplier is two, so you double the depth of the offset, and you have the distance to mark between the bends. And when the handle of the bender is straight up and down, the bend is thirty-degrees, and you don't have to check the markings. Twenty-twos would be nice, thirties are easiest, and never put in forty-fives: they're a bitch to pull wires through. (Racca et al. 2000, p. 12)

This field note shows that $30^{\circ}$ angles are chosen because the multiplier is easily remembered, even though a $22.5^{\circ}$ angle would make pulling the wire through the conduit much easier. Moreover, because the $30^{\circ}$ angle corresponds to a vertical handle of the tool, the markings do not have to be checked but the correct bend is achieved when the handle is vertical. There is also an issue of working with the bender when the work has to be conducted in dangerous settings, such as three stories up on a scaffold, where the footing consists of no more than $3 / 4$-inch plywood sheets.

Electricians also develop methods that do not use specific angles at all. We documented one instance, where a journeyman explained to a fourth-year apprentice how to bend electrical conduit tubing without using any angle measurement at all. The tubing is bent at an arbitrary angle and then placed against a wall. The correct length is achieved by moving a square alongside the wall until the distance to the wall-oriented side of the pipe surface corresponds to the desired offset. The tubing is marked and the conduit tubing bent at the mark until the pre- and post-offset pipes are parallel. In this manner, no calculations are required at all because the process has been reduced to a simple measurement of distance.

Whereas in their college course, apprentices practice on relatively short pieces of metal, in the field they have to work with the conduit tubing that will cover the entire lineal distance. This is an important issue, as the termination of rigid tubing - involving cutting, reaming, and threading - has to be accomplished prior to bending. Because of the offsets introduced, the lineal distance and the length of the pipe required do not coincide. Whereas 
tables exist that tell the electrician how much the conduit "shortens" for each offset and offset angle, most electricians in our study adjusted the length by using a hacksaw or adjusted to nearby fittings by inserting tubing less than the recommended amount into the counterpart. Rules of bending thereby also included the bending of rules.

\subsection{Electrical apprentices between college and workplace}

At the college, many apprentices struggle with the tasks that require application of trigonometry and precise calculations of the pertinent quantities. Many students attending the program including our observer participant complained and called into question the usefulness of the pre-apprenticeship program and apprenticeship training courses. Students describe their experience as "putting in time" that moves them along their training trajectory. This is not unlike what we observe in other programs - such as the mariners we studied returning to upgrade their certificates (Emad \& Roth, 2008). Here, too, both students and instructors knew that the course contents were irrelevant to the worksite, but both parties colluded so that students were properly prepared - in contrast with being more proficient on the worksite - to succeed in formal examinations on the basis of which they would receive their certificates. For the students, college is the place where "mathematics and science are taught," which contrasts with the workplace, "where the real job gets done." There are therefore inherent tendencies toward a schism, where the college emphasizes learner subjectivities and theory and where the workplace emphasizes workers and their practical competencies. It might be tempting to theorize the apprentices' backand-forth movements between college and work by means of the boundary crossing concept. However, my research generally suggests that the gap between theory and practice becomes part of the professional lore.

Much as in the fish hatcheries and mariner training programs we studied (Emad \& Roth, 2008; Lee \& Roth, 2004), the difference between college and work has its own discourse that allows the interaction participants to draw on the difference as a resource or topic. 
There are frequent articulations of differences between college and workplace methods, such as when journeymen and more senior apprentices point out, in the context of a specific job, how something would be taught in college and how things have to be done "in the real world" and "on the job."

Some of the students, like the apprenticeship researcher, do learn the theoretical discourse which enables them to tell more junior colleagues about the differences between college and work discourse about how the job is to be done - for example, how to correctly cut, ream, measure, and bend electrical conduit tubing. The gap between the formal and work discourses appears to arise from an epistemology that "tends to endorse the valuation of abstract knowledge over actual practice and, as a result, to separate learning from working, and, more significantly, learners from workers" (Brown \& Duguid, 1991, p. 41). Our ethnographic work shows that the electrical apprentices are treated on the job as workers rather than as learners, even though the differences in status are acted out in that the apprentices were asked to do the undesirable and repetitive tasks.

An important site for the knotworking between college, code, and work practice was the course on Canada's electrical code; as part of the formal educational setting, it therefore differs from the informal settings (e.g., bars) where field ecologists learn much of their trade (Roth \& Bowen, 2001). Electrician apprentices spend a week in groups working through the code and completed worksheet assignments. They had discussions with the instructor, who also debriefed them. In this course, stories from the field constituted an important resource for making sense of the code, which, in turn, led to a discourse in which the familiar material practices were en-coded, that is, retold in terms of the Canadian electrical code. Our ethnography shows that students actively drew on their own workrelated experiences and on the stories of others to respond to the examination questions of the course. The stories produced the knot where code and (stories of) praxis came together while taking a formal college course. Because of the relation between the two aspects, firstyear apprentices acquire a form of knowledge that more closely resembles case law than 
the law as written. The ability to retell practical decision making and practical work in terms of the code is important, as it allows the practitioner to articulate the legality of what they have done. It is also an important aspect of thinking about the integration of two lifeworld - college and work - rather than their differentiation into very different worlds that require border crossing to get from one into the other. That is, apprentice and licensed electricians point out the contradictions between the formal knowledge taught in college and their everyday practices and these contradictions are integral part of the stories they tell. But the contradiction is apparent in their work, because the electricians do their jobs in such a manner that these meet the demands of the code - though it would be a stretch to argue that the code drives or shapes the practice.

As apprentices participate in worksites, they become increasingly competent practitioners, recognized by their peers for the contributions that they make to the job at hand. Increasing subjectification - i.e., becoming a subject of activity - also means building up a stock of stories that practitioners share with others in appropriate instances. In fact, the stories not only encode practical knowledge but also the very process of subjectification, as can be seen in the following field note, in which the apprentice talks about a new workplace:

After months of being a disposable set of hands on the big industrial site, working with Steve just about brings on culture shock. I've shed my fifteen-pound tool belt, and walk around with a "data geek" pouch with precision cutters and termination tools. I've been introduced to, and routinely discuss my work with, the network manager, a system analyst, and a couple of programmers. I'm a player in a team, not just of electricians, but of network builders. I wear a dress shirt to work, and my jeans stay clean. Some of the guys at the other site say that data is for sissies, but I happen to like it (maybe they're just envious).

In this new worksite, the very comportment and dress is constitutive of the subject, and appearing differently than others would be an affront to the team as a whole. A 15-pound 
tool belt is the appropriate attire in one situation, whereas precision cutters are characteristic of the other. Attire and tools are constitutive of who the apprentice becomes, and, therefore, of the process of subjectification characteristic of the particular activity system.

\section{Subjectification, personality, and the demise of boundaries}

This study was designed to investigate (a) the geometrical practices of electrician apprentices in college and on the job and (b) how the relation between differing practices come to be handled. From the cultural-historical activity theoretic perspective underlying this study, college and workplace belong to different forms of activity. Because activity is the minimal unit that makes sense (Leontjew, 1982), participating in a different activity means that the person is differently constituted as subject in each activity system. This process of subject development is denoted by the term subjectification. Boundary crossing theories (see review in Akkerman \& Bakker, 2011) tend to theorize the differences that arise from being a different subject and engaging in different practices in terms of boundaries that the person has to cross. The present study shows, however, that the apprentices integrate these differences between school and workplace not only by living through them in person but also by accounting for these differences in their workplace stories and narratives about work. Moreover, this study shows that "workplace" is not a unitary experience but that an apprentice may be subject to "culture shock" when s/he moves from one type of electrical work to another. Thus, the foregoing data show that Racca was constituted as a very different subject while working on construction and while building computing networks. From a cultural-historical activity theoretic perspective, each form of subjectivity that the subject-related differences imply is but a knot in a much more complex knotwork that in its entirety constitutes the personality.

In the course of their apprenticeship arrangement, electricians spend 3 months at college and 9 months at work during each of the 4 years of the training. Therefore, the 
apprentices in this program experience 7 times the transition from college to work and vice versa. The transitions, as much as the subjectivities that are aspects of each particular activity, are therefore integral to becoming and being a certified electrician journeyman and, thus, constitutive of the person, that is, constitutive of his/her personality. In the process, the individual electrician also comes to embody the contradictions between the different activity systems, contradictions that are aspects of the stories that contribute to making a licensed journeyman electrician who s/he is. But they come to embody these contradictions in different ways, because the knots related to workplace and college activity appear in different locations in their individual knotworks and, therefore, not only constitute different personalities but also constitute these differently. Thus, for Racca the journeyman certification was but one of the possibilities of earning a living and he never worked full-time in the profession following his licensure; other participants in our study were at the beginning of their career, and becoming a journeyman electrician was the first thing they did following high school; and yet others had worked on the job, going through the apprenticeship training only to become certified to legally do what they have already done. There is therefore both an experienced contradiction between college and workplace forms of knowledge and subjectivities and a differential integration of these contradictions into the total knotwork that constitutes the personality of each apprentice. Having a stock of stories to talk about the contradictions is as much part of being a recognized practitioner as is competent practice, the narratives that encode the do's and don't's of the workplace, the translations between practice and formal code, and the justifications that a job done is in fact consistent with and implements the code.

This study among electricians and electrician apprentices exhibits the radical differences between the (mathematical) practices of bending electrical metal tubing in college and in the workplace. As could be expected from cultural-historical activity theory, the forms of consciousness that they exhibit to each other also are radically different, in part related to the different tools that are available or that must be used (trigonometry in 
college, bender in workplace praxis). This raises questions as to the usefulness of vocational courses that emphasize formal mathematics that is treated as irrelevant in the workplace. Similar contradictions arise when new tools are introduced to the work; these contradictions give rise to old-timer stories about what they do with the old tools where users of new tools "screw up." In this case, we might be tempted to use boundary crossing as the pertinent analytic category. However, I suggest that this is neither necessary nor useful. Instead we may draw on personality as the relevant analytic category. It orients us to the knotwork of object/motives that holds together the different activities in which a person participates, together with the category of subjectification. This pair of analytic categories describes and theorizes the experience of the persons much better than boundary crossing as they articulate the differences all the while integrating them into a higher order (dialectical) unit. It better aligns with a science of the subject, where the viewpoints of persons on learning take precedence over the theoreticians' perspectives that are characteristic of the social sciences (e.g., Holzkamp, 1993). After all, even though the electrical apprentices felt formal mathematics as unhelpful and useless, they repeatedly moved back and forth between the different activities with a sense of coherence: "Because our true body is a subjective body it is the unity of all the powers, of all the senses that make it up" (Henry, 2005, p. 192, emphasis added).

Going to college as part of the apprenticeship program, however despised, is an integral part of becoming a licensed electrician. At work, nobody uses the trigonometry that they have to learn to pass the test and get their license. But it is part of the process of subjectification within schooling, a process that most participants feel subject and subjected to. In the workplace, however, especially the more advanced electrician apprentices experience greater levels of agency, even though during their first year they are often subjected to workplace-specific demands, such as doing the least-liked and appreciated aspects of the total project. Most importantly, having gone to college allows the journeyman electricians to work according to the electrical code all the while meeting practical 
workplace constraints. In fact, they have to know that their job meets legal standards, as all electrical work is subject to formal inspection by a member of the Electrical Inspectors' Association of British Columbia, which had been created to achieve uniform interpretation of the code.

There are not just differences between college and workplace: the electricians' discourse about those differences is both topic and resource in the conversations that constitute their community of practice. The integration and differentiation of the two forms of practices is an integral aspect of being a practicing electrician (as it is an integral part of the mariners, fish culturists, or ecologists we studied). Electricians often make reference to what is taught and what is done much in the same way that they refer to the Code when talking about what is "the law" and what is being done. Leontjew's category personality appears appropriate because it focuses on the integration of the different object/motives (activities) and their hierarchical ordering of knots rather than merely on the boundaries between them. The location of the college and workplace knots in the individual electrician's hierarchy may change in and through participation in an activity - which allows us to understand that some practitioners eventually move from practice to become teachers in college programs. The embedded researcher in this study (Racca) used his MA study as a resource to become part of a government panel on learning assessment and the trades while in his third year of his four-year program. That is, the electrician apprentices undergo two processes of subjectification by participating in the college and workplace, being both subjects of and subject(ed) to the activities. They integrate these as part of the electrician personality they develop, which in fact constitutes a knotwork that holds the respective experiences together in the same person, but attributing different places to these in the resulting hierarchy.

There is transfer (i.e., "knot-working") of practices to the extent that the stories they tell when making sense of problematic issues are carried from one activity (e.g., schooling) to the other (e.g., doing electrical work). In workplace stories, there are references to the 


\section{Coda}

Using a case study from the apprenticeship programs and training of electricians, I outline a cultural-historical activity theoretic approach to the question of the discontinuities of social practices. I propose subjectification and personality as a set of analytic categories to capture the continuity of experiences that an individual person feels even if $\mathrm{s} /$ he moves across activities implying different subjectivities and, therefore, engages in different cultural practices where $\mathrm{s} /$ he is constituted differently as the subject of activity. 


\section{References}

Akkerman, S. F., \& Bakker, A. (2011). Boundary crossing and boundary objects. Review of Educational Research, 81, 132-169.

Brown, J. S., \& Duguid, P. (1991). Organizational learning and communities-of-practice: Towards a unified view of working, learning, and innovation. Organization Science, 2, 40-57.

Canadian Standards Association (CSA). (2003). Radii of bends in raceways, Rule 12-922(1) and Table 7. Accessed September 15, 2010 at www.electricalcontractor.net/Forum/International/Subject2914.PDF

Cox, R. A. (1982). Electricians guide to conduit bending. Spokane, WA: Pend Oreille.

Coy, M. W. (Ed.). (1989). Apprenticeship: From theory to method and back again. Albany, NY: State University of New York.

Emad, G., \& Roth, W.-M. (2008). Contradictions in practices of training for and assessment of competency: A case study from the maritime domain. Education and Training, 50, $260-272$.

Greenlee Textron. (1998). Instruction manual: Site-rite hand benders 840, 841, 842, 843, 840H, 841H and 842H AND Site-Rite II handbenders 8840, 8841, 8842, 8843, 8840H, $8841 H$, and $8842 H$. Rockford, IL: Author.

Henry, M. (2005). Voir l'invisible: Sur Kandinsky [Seeing the invisible: On Kandinsky]. Paris: Presses Universitaires de France.

Holzkamp, K. (1993). Lernen: Subjektwissenschaftliche Grundlegung [Learning: A subjectscientific foundation]. Frankfurt: Campus.

Knight, P. S. (2002). Electrical code simplified: Residential. Sechelt, BC: Author.

Lave, J. (1988). Cognition in practice: Mind, mathematics and culture in everyday life. Cambridge, UK: Cambridge University Press. 
Lee, Y. J., \& Roth, W.-M. (2004). They've gotta learn something unless they're just out to lunch: Becoming an expert in a salmon hatchery. Anthropology of Work Review, XXV (12), 15-21.

Lee, Y-J., \& Roth, W.-M. (2006). Learning about workplace learning and expertise from Jack: A discourse analytic study. Journal of Workplace Learning, 14, 205-219.

Lee, Y. J., \& Roth, W.-M. (2007). The individual|collective dialectic in the learning organization. The Learning Organization, 14, 92-107.

Leontjew, A. N. (1982). Tätigkeit, Bewusstsein, Persönlichkeit [Activity, consciousness, personality]. Köln: Pahl-Rugenstein.

Marx, K., \& Engels, F. (1962). Werke Band 23: Das Kapital. Kritik der Politischen Ökonomie. Erster Band [Works vol. 23: Capital. Critique of political economy]. Berlin: Dietz. Nancy, J-L. (1993). Éloge de la mêlée [In praise of the mêlée]. Transeuropéenne, 1, 8-18. Noss, R., \& Hoyles, C. (1996). The visibility of meanings: Modelling the mathematics of banking. International Journal of Computers for Mathematical Learning, 1, 3-31.

Racca, R., Bowen, G. M., \& Roth, W.-M. (2000). Learning scientific practices in the electrical trade: Implications for educational programs. Paper presented at the 2000 annual meeting of the American Educational Research Association, New Orleans, LA. Accessed September 15, 2010 at URL www.educ.uvic.ca/faculty/mroth/conferences/CONF2000/RACCA3.pdf

Rancière, J. (1999). Dis-agreement: Politics and philosophy. Minneapolis: University of Minnesota Press.

Roth, W.-M. (2005). Mathematical inscriptions and the reflexive elaboration of understanding: An ethnography of graphing and numeracy in a fish hatchery. Mathematical Thinking and Learning, 7, 75-109.

Roth, W.-M. (in press). Apprenticeship: Toward a reflexive method for researching “education in 'non-formal' settings." In S. Delamont (Ed.), Handbook of qualitative research in education. Camberley, UK: Edward Elgar. 
Roth, W.-M., \& Bowen, G. M. (2001). Of disciplined minds and disciplined bodies. Qualitative Sociology, 24, 459-481.

Roth, W.-M., \& Lee, Y. J. (2007). “Vygotsky's neglected legacy”: Cultural-historical activity theory. Review of Educational Research, 77, 186-232.

Roth, W.-M., \& Radford, L. (2011). A cultural-historical perspective on mathematics teaching and learning. Rotterdam, The Netherlands: Sense Publishers.

Saxe, G. B. (1991). Culture and cognitive development: Studies in mathematical understanding. Hillsdale, NJ: Lawrence Erlbaum Associates.

Schliemann, A. D., \& Acioly, N. M. (1989). Mathematical knowledge developed at work: The contribution of practice versus the contribution of schooling. Cognition and Instruction, $6,185-221$.

Scribner, S. (1986). Thinking in action: some characteristics of practical thought. In R. J. Sternberg \& R. K. Wagner (Eds.), Practical intelligence: Nature and origins of competence in the everyday world (pp. 13-30). Cambridge: Cambridge University Press.

Tuomi-Gröhn, T., \& Engeström, Y. (Eds.). (2003). Between school and work: New perspectives on transfer and boundary-crossing. Amsterdam: Pergamon.

Vygotsky, L. S. (1989). Concrete human psychology. Soviet Psychology, 27(2), 53-77. 
Figure 1 (b\&w figure)

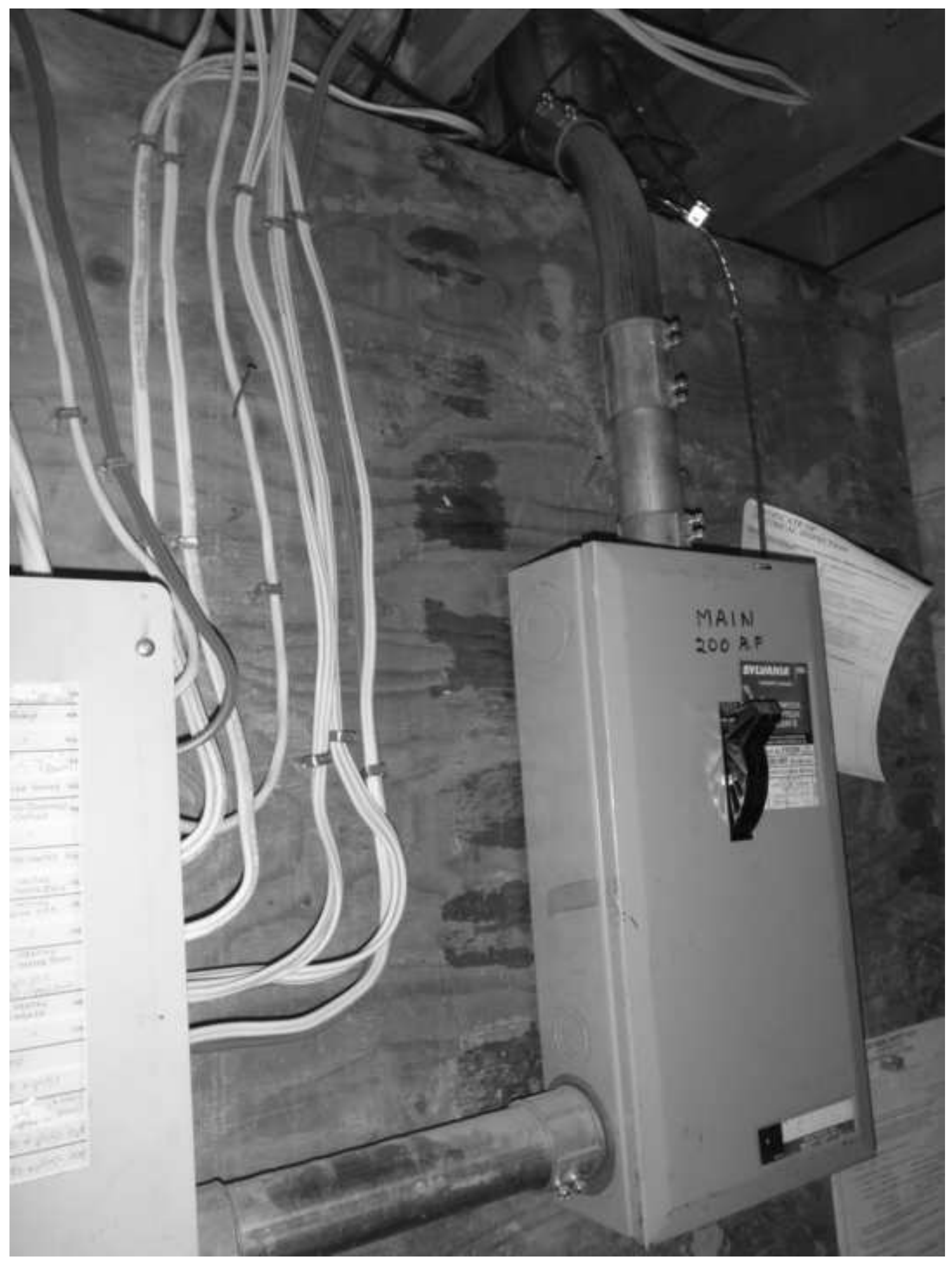

\section{Figure 1 (b\&w figure)}

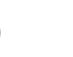

Figure 1 (b\&w figure)

列

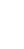

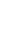

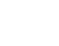



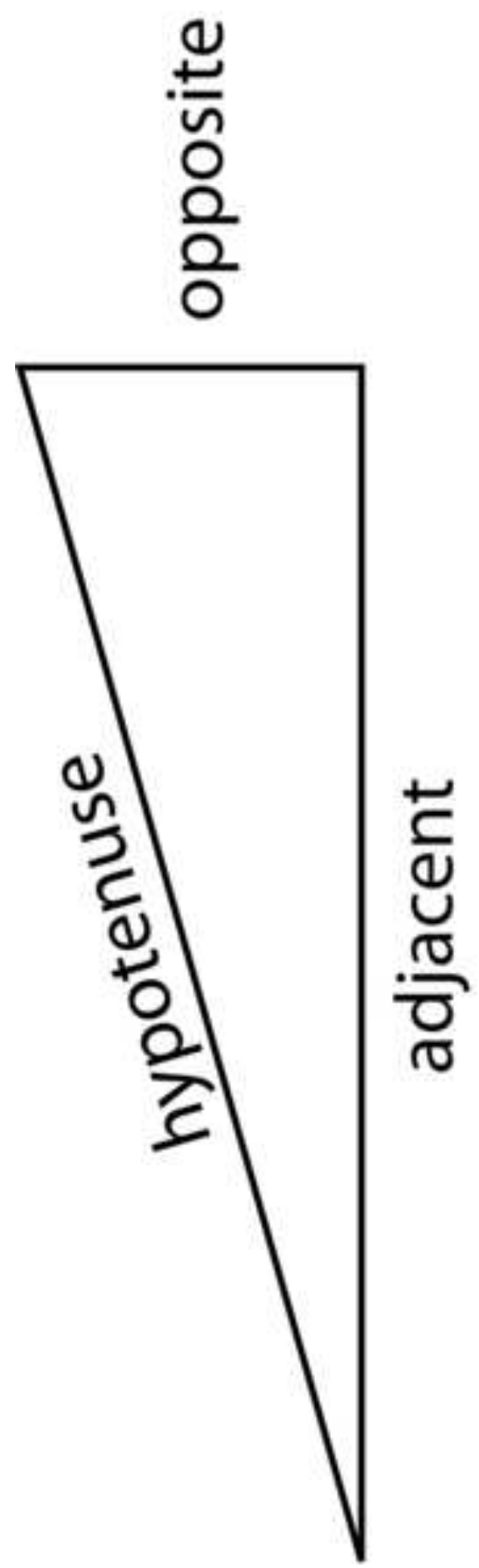
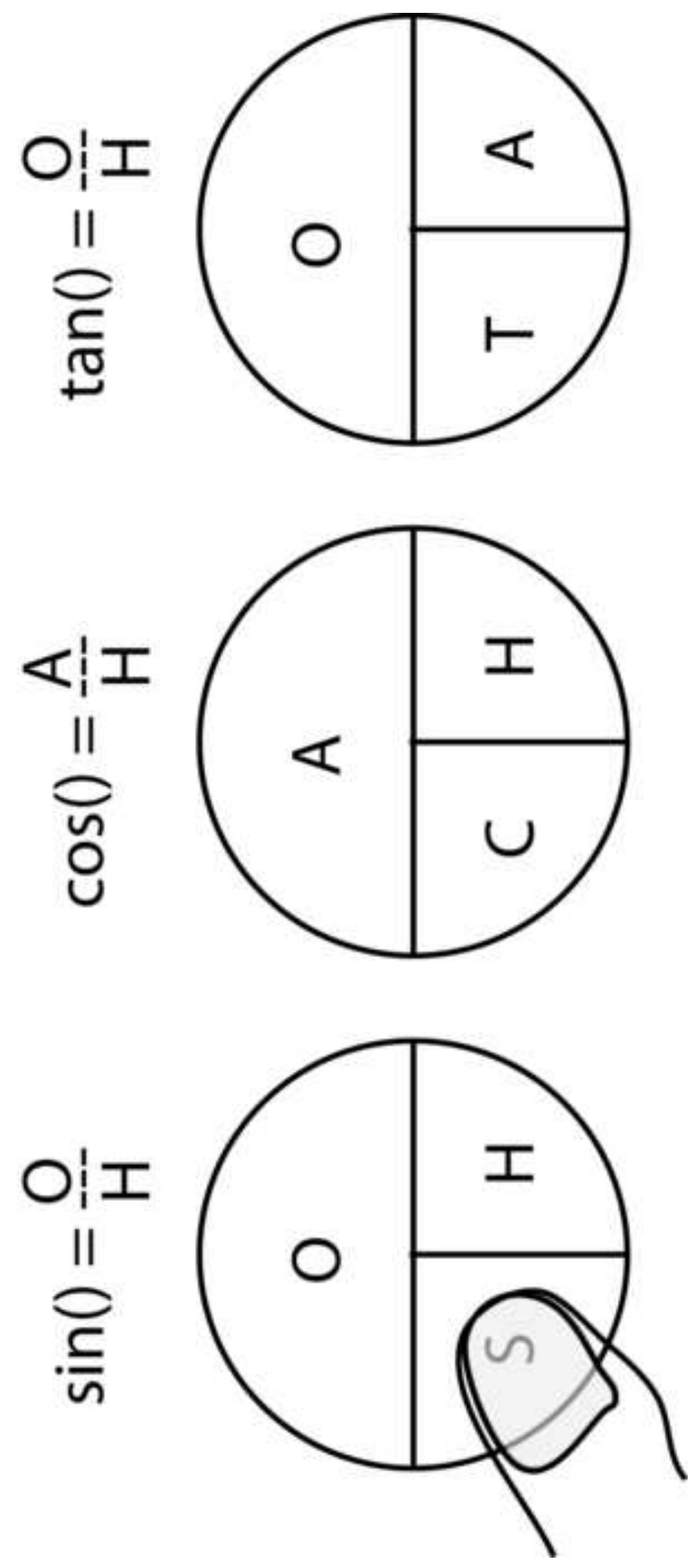


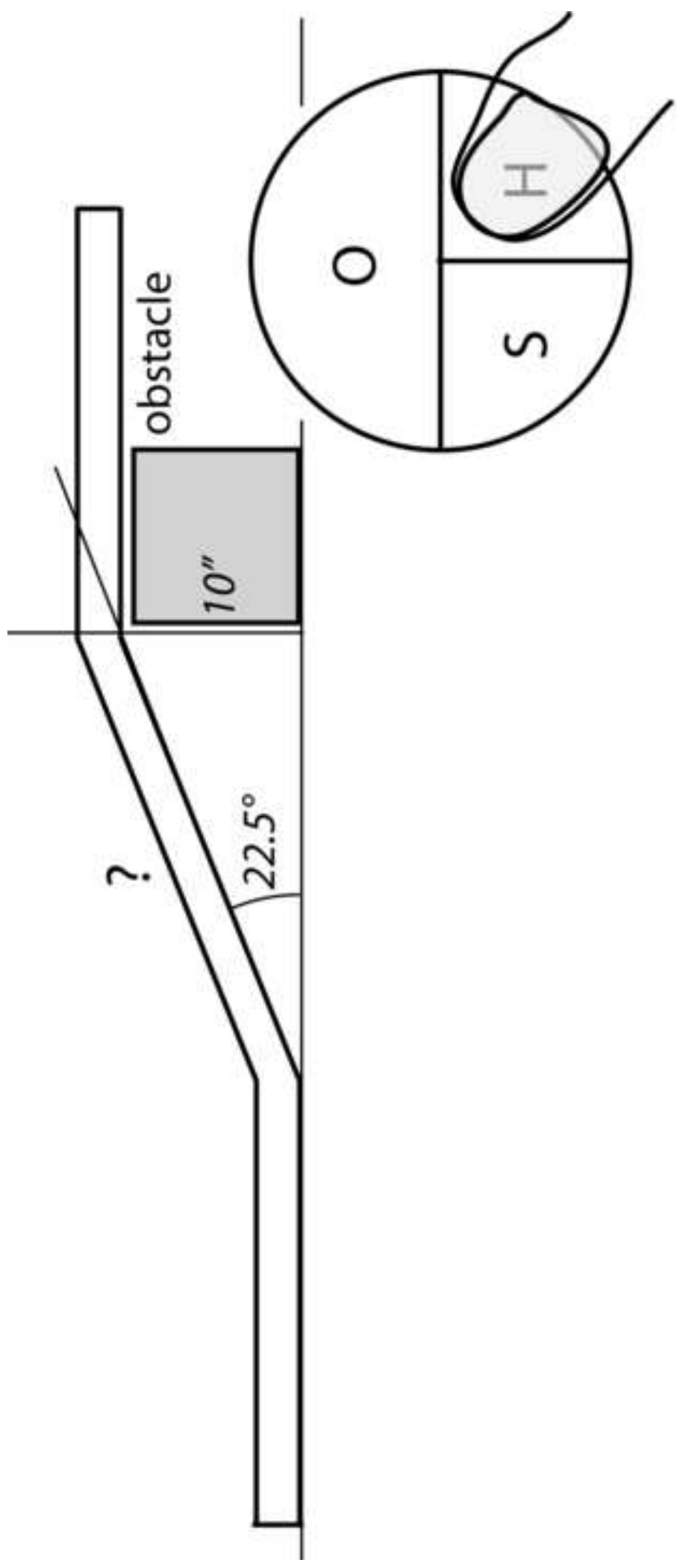


Figure 4 (b\&w photo)
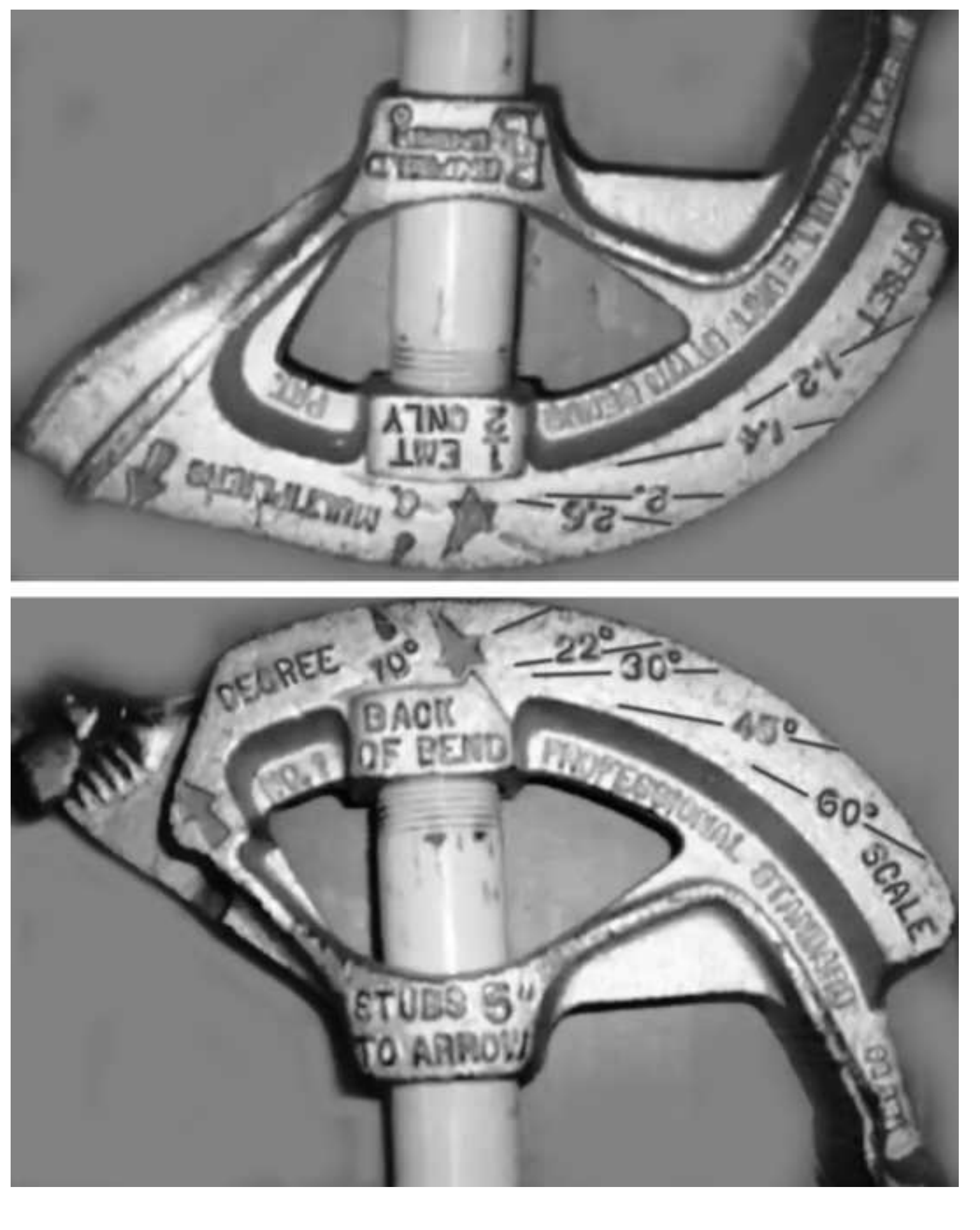

$$
2 \text { - } 120
$$

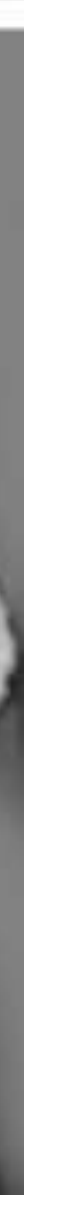

Figure 4 (b\&w photo)

)
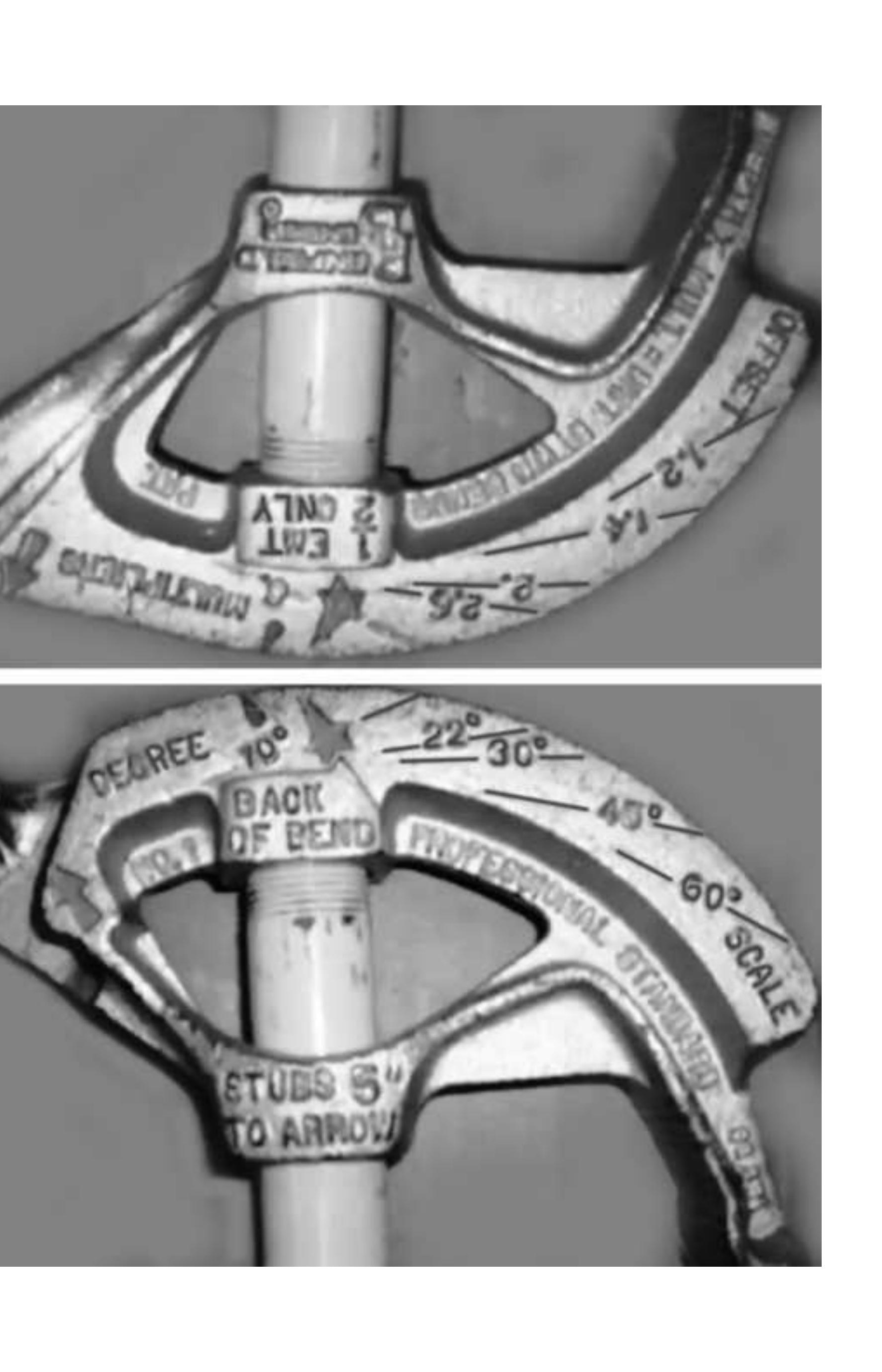

de

.

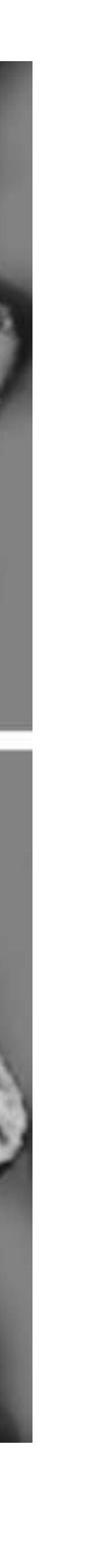

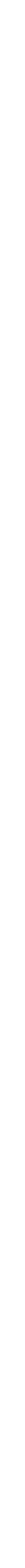




\section{Captions}

Figure 1. Electrical metal conduit into the main breaker panel and between breaker panels protects and grounds the wires; the "Certificate of Inspection" on the right guarantees that the house has been wired according to the Electrical Code of Canada. Electricians endeavor to have as few of the visible joining pieces as possible.

Figure 2. The magic circle is a device that is to assist students in remembering how to calculate trigonometric functions.

Figure 3. In college, electrician apprentices are asked to use trigonometry to decide where bends in a parallel offset have to be placed, how far from the object, and what the distance between the bends are given the bending angle.

Figure 4. This front and back view of a bender shows that much of the information required in praxis is engraved on the tool. 